\title{
Socio-demographic Determinants of Low Physical Activity in Peruvian Adults: Results of a Population-based Survey Performed in 2017-2018
}

\author{
Akram Hernández-Vásquez' ${ }^{1}$ Rodrigo Vargas-Fernández ${ }^{2}$ \\ ${ }^{1}$ Centro de Excelencia en Investigaciones Económicas y Sociales en Salud, Vicerrectorado de Investigación, Universidad San Ignacio de Loyola, Lima, \\ Peru; ${ }^{2}$ Facultad de Ciencias de la Salud, Universidad Científica del Sur, Lima, Peru
}

Objectives: The objective of this study was to determine the prevalence of low physical activity (PA) in Peruvian adults and to identify associated factors.

Methods: An analytical study was performed using data from the 2017-2018 Nutritional Food Surveillance by Life Stages survey. The outcome variable was low PA (yes or no), assessed using the International Physical Activity Questionnaire-short form. Prevalence ratios were estimated as a measure of association.

Results: Among the 1045 persons included in the analysis, the age-standardized prevalence of low PA was $61.9 \%$. The adjusted model showed that being female and migrating from a rural to an urban area in the last 5 years were associated with a higher probability of having low PA than males and individuals who had not migrated, while residing in rural highlands and jungle areas was associated with a reduced probability of having low PA compared to people residing in other geographic domains.

Conclusions: Being a female and migration from a rural to an urban area in the last 5 years were associated with a higher likelihood of having low PA. Therefore, promotion and prevention strategies related to PA are required, especially in the female and migrant populations.

Key words: Physical activity, Public health surveillance, Population surveillance, Peru

\section{INTRODUCTION}

Physical inactivity is a global health problem that increases the risk of cardiovascular disease, type 2 diabetes, obesity, and

Received: July 26, 2021 Accepted: October 30, 2021

Corresponding author: Akram Hernández-Vásquez

Centro de Excelencia en Investigaciones Económicas y Sociales en

Salud, Vicerrectorado de Investigación, Universidad San Ignacio de

Loyola, 550 La Fontana Avenue, La Molina, Lima 15024, Peru

E-mail: ahernandez@usil.edu.pe

This is an Open Access article distributed under the terms of the Creative Commons Attribution Non-Commercial License (https://creativecommons.org/licenses/by$\mathrm{nc} / 4.0 / /$ which permits unrestricted non-commercial use, distribution, and reproduction in any medium, provided the original work is properly cited. cancer, and impairs health-related quality of life [1-4]. Worldwide, more than a quarter of the population does not get enough physical activity (PA), with a $4.2 \%$ increase in the number of people between 2010 and 2016 [5]; furthermore, physical inactivity is more prevalent among females and in countries with high income inequality [6]. In 2019, low PA caused more than 800000 deaths and generated 12.7 million years of life lost due to premature mortality, 3.1 million years lived with a disability, and 15.7 million disability-adjusted life years (DALYs), making it the 18th leading cause of DALYs globally [7]. In addition, physical inactivity generates high health costs due to a higher incidence of preventable diseases [8], mainly in lowincome and middle-income countries, in which there is a high 
burden of disease and mortality from non-communicable diseases (NCDs) $[9,10]$.

Latin America and the Caribbean (LAC) constitutes one of the least developed regions with one of the highest levels of urbanization in the world. Approximately $20 \%$ of inhabitants live in overcrowded conditions, with high levels of crime and violence in urban areas, high levels of poverty, and a lack of leisure-time PA facilities [11]. In this context, LAC has the highest prevalence of low PA compared to other regions of the world [5] and is considered one of the regions with the highest burden of disease [12] and economic burden [13] due to NCDs. In addition to this problem, in middle and low-income countries such as Peru, the effectiveness, implementation, and availability of policies related to PA through promotion and prevention programs are low to moderate [14].

In Peru, there are different patterns of physical inactivity due to the characteristics of the areas or regions where people live. Thus, in urban areas, it has been reported that people have a higher prevalence of physical inactivity due to the greater amount of motorized transport and higher consumption of carbohydrates and sugary foods compared to residents of rural areas, who have a high prevalence of PA related to manual labor $[15,16]$ and transportation on foot due to the lack of paved roads, bicycle paths, and recreational spaces [15]. In addition, it has been observed that the female population - with associations with low socioeconomic level and overweighthas a higher prevalence of physical inactivity, regardless of the region in which the individual resides $[17,18]$. Although some previous studies have investigated physical inactivity in the Peruvian population [17-20], it is necessary to obtain updated information, since lifestyles may change over time due to migration, increased urbanization, and a lack of promotion of good health practices [21].

Therefore, the objective of the present study was to determine the prevalence of low PA in the Peruvian population and to identify associated factors.

\section{METHODS}

\section{Subjects and Data Source}

This was an analytical, cross-sectional, population-based study of the 2017-2018 Food and Nutrition Surveillance by Life Stages survey (VIANEV: acronym in Spanish), which was conducted by the National Food and Nutrition Center of the National Institute of Health of Peru [22]. The 2017-2018 VIANEV survey was representative at the country level, as well as Metropolitan Lima, and urban and rural areas. The survey sample included adults aged 18 years to 59 years old residing in households from a subsample of the National Household Survey (ENAHO: acronym in Spanish) during the first quarter of 2017. The sampling was probabilistic, multistage (at the level of clusters and dwellings), and with a random start. The level of inference is at the national, urban, rural and Metropolitan Lima (capital of Peru) levels. Further details of the methodology can be found in the Technical Report of the 2017-2018 VIANEV survey [22].

The 2017-2018 VIANEV survey was conducted through faceto-face interviews by trained staff according to a standardized protocol. A pilot study was also conducted in order to strengthen the application of the techniques and adjust the procedures conducted by the trained personnel [22].

The survey included a total of 1073 subjects, of whom 1045 were included in the present study according to the following inclusion criteria: (1) subjects aged 18 years to 59 years, and (2) complete data on PA levels. The exclusion criterion was incomplete data on socioeconomic, demographic, and health status information. Details on the sample selection procedure are shown in Figure 1.

\section{Variables}

\section{Outcome variable}

The main study variable was the level of PA, assessed by means of the short version of the International Physical Activity Questionnaire (IPAQ). The IPAQ is widely used in different countries and socioeconomic contexts. This questionnaire collects self-reported information on PA and sedentary behavior of people aged 15-69 years. There is a short and long version of this questionnaire, with the short version assessing 3 characteristics of PA: frequency (days per week), duration (time per day) and intensity (mild or walking, moderate, or vigorous). Intensity is recorded using metabolic equivalent-task units (METs) per minute and per week, in which walking has 3.3 METs, moderate activity has 4.0 METs, and vigorous activity has $8.0 \mathrm{METs}$; the total level of activity is calculated by multiplying each MET value by the number of days per week and the time in minutes of each activity. PA is divided into 3 categories (low, moderate, and high), depending on the intensity, frequency, and duration of the activity performed [23]. For the present study, individuals were classified as having low PA (yes or no), which was defined as reporting no PA or fewer than 3 days of vigorous 


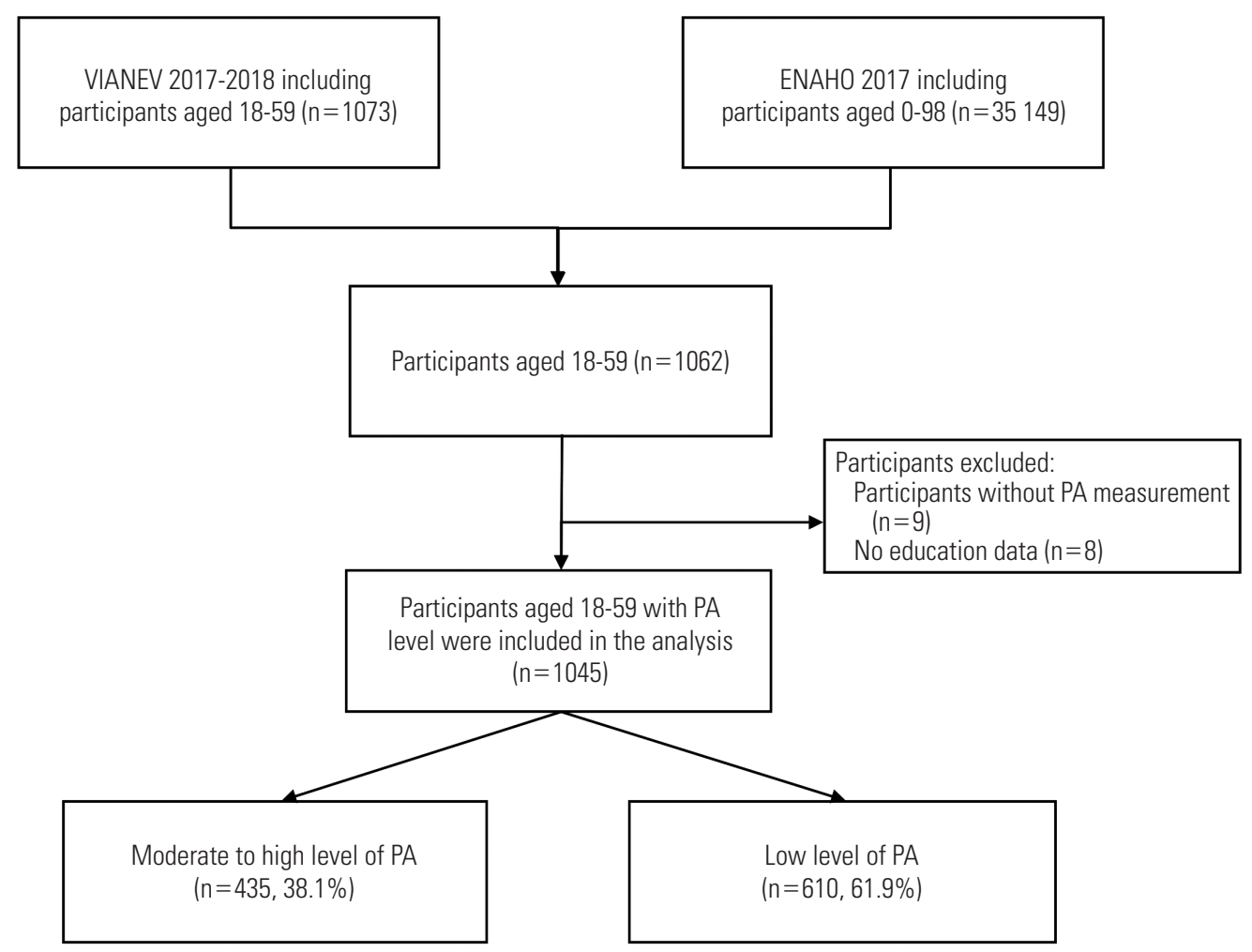

Figure 1. Flow chart of participants included in the study analysis. VIANEV, 2017-2018 Food and Nutrition Surveillance by Life Stages survey; ENAHO, National Household Survey; PA, physical activity.

activity with less than $20 \mathrm{~min} / \mathrm{d}$, fewer than 5 days of moderate activity and/or walking less than $30 \mathrm{~min} / \mathrm{d}$, or fewer than 5 days of any combination of walking and moderate or vigorous activities achieving less than $600 \mathrm{METs}-\mathrm{min} / \mathrm{wk}[19,22]$.

\section{Explanatory variables}

We adopted the conceptual framework of Pettee Gabriel et al. [24] to determine the explanatory variables. These variables have been identified in previous studies as being associated with PA $[17,19,20,25]$. The explanatory variables considered in the analysis were: sex (male or female), age groups (18-29, 30-39, 40-49, or 50-59 years), educational level (up to primary, secondary, or higher education), ethnicity (non-native or native), self-reporting of the presence of chronic diseases (yes or no), self-reporting of the presence of any physical, psychological or cognitive limitation (yes or no), geographic domain of residence (urban coast, rural coast, urban highlands, rural highlands, urban in jungle, rural areas in jungle, or Metropolitan Lima), poverty level (extreme poverty, non-extreme poverty, or non-poverty), having worked in the last week (yes or no), migration to an urban area in the last 5 years (yes or no), and altitude above sea level of household residence $(0-499,500$ -
$1499,1500-2999$, or $\geq 3000$ meters). In terms of geography, the coast is the region that borders the Pacific Ocean and is home to the main cities of Peru; the highlands are made up of the area of the Andes mountain range; and the jungle is the Amazon region, which has the greatest biodiversity in Peru.

\section{Statistical Analysis}

Data management and analysis were performed using Stata version 14 (StataCorp., College Station, TX, USA). The 2017-2018 VIANEV survey databases were merged with the ENAHO 2017 databases, which are freely available on the National Institute of Statistics and Informatics (INEl: acronym in Spanish) website (http://iinei.inei.gob.pe/microdatos/), using the merge command according to the identifiers of stratum, conglomerate, dwelling, household, and individual (Figure 1). The expansion factor and sample specifications of the 2017-2018 VIANEV survey design were taken into account for all analyses using the svy command. A $p$-value $<0.05$ was considered to indicate statistical significance.

The variables of interest were described using absolute frequencies and their weighted proportions together with their 95\% confidence intervals (Cls). The age-standardized preva- 
Table 1. Characteristics of the participants included in the study

\begin{tabular}{|c|c|c|c|c|}
\hline \multirow{2}{*}{ Characteristics } & \multirow{2}{*}{ n (\%) } & \multicolumn{2}{|c|}{ Low physical activity } & \multirow{2}{*}{ p-value ${ }^{1}$} \\
\hline & & Yes & No & \\
\hline Overall & $1045(100)$ & $61.9(58.2,65.5)^{2}$ & $38.1(34.5,41.8)^{2}$ & \\
\hline Male & $439(41.4)$ & $55.5(50.1,60.7)$ & $44.5(39.3,49.9)$ & 0.002 \\
\hline Female & $606(58.6)$ & $66.3(61.6,70.7)$ & $33.7(29.3,38.4)$ & \\
\hline $30-39$ & $265(24.9)$ & $63.3(56.5,69.6)$ & $36.7(30.4,43.5)$ & \\
\hline $40-49$ & $250(24.2)$ & $56.0(48.6,63.2)$ & $44.0(36.8,51.4)$ & \\
\hline $50-59$ & $207(18.9)$ & $65.6(58.3,72.2)$ & $34.4(27.8,41.7)$ & \\
\hline \multicolumn{5}{|l|}{ Educational level } \\
\hline Up to primary & $262(19.0)$ & $56.3(49.2,63.2)$ & $43.7(36.8,50.8)$ & 0.013 \\
\hline Non-native & $789(77.6)$ & $62.1(57.9,66.1)$ & $37.9(33.9,42.1)$ & 0.755 \\
\hline Native & $256(22.4)$ & $60.7(52.9,68.1)$ & $39.3(31.9,47.1)$ & \\
\hline \multicolumn{5}{|c|}{ Self-reported presence of chronic diseases } \\
\hline No & $609(57.6)$ & $61.1(56.2,65.7)$ & $38.9(34.3,43.8)$ & 0.626 \\
\hline Yes & $436(42.4)$ & $62.8(57.4,67.9)$ & $37.2(32.1,42.6)$ & \\
\hline \multicolumn{5}{|c|}{ Self-reported presence of any physical, psychological, or cognitive limitations } \\
\hline No & 1023 (98.4) & $61.9(58.2,65.5)$ & $38.1(34.5,41.8)$ & 0.702 \\
\hline Yes & $22(1.6)$ & $57.3(33.8,77.9)$ & $42.7(22.1,66.2)$ & \\
\hline \multicolumn{5}{|l|}{ Geographic domains } \\
\hline Urban coast & $126(14.3)$ & $70.9(60.5,79.5)$ & $29.1(20.5,39.5)$ & $<0.001$ \\
\hline \multicolumn{5}{|l|}{ Poverty } \\
\hline Extreme poverty & $37(2.3)$ & $34.4(20.8,51.2)$ & $65.6(48.8,79.2)$ & 0.014 \\
\hline Non-extreme poverty & $163(13.4)$ & $62.7(54.2,70.5)$ & $37.3(29.5,45.8)$ & \\
\hline Non-poverty & $845(84.3)$ & $62.4(58.3,66.4)$ & $37.6(33.6,41.7)$ & \\
\hline \multicolumn{5}{|l|}{ Worked in the last week } \\
\hline No & $283(30.3)$ & $66.5(59.7,72.7)$ & $33.5(27.3,40.3)$ & 0.080 \\
\hline Yes & $762(69.7)$ & $59.8(55.6,63.8)$ & $40.2(36.2,44.4)$ & \\
\hline \multicolumn{5}{|c|}{ Urban migration in the last $5 y$} \\
\hline No & $994(94.8)$ & $60.9(57.1,64.5)$ & $39.1(35.5,42.9)$ & 0.019 \\
\hline Yes & $51(5.2)$ & $78.9(64.0,88.7)$ & $21.1(11.3,36.0)$ & \\
\hline \multicolumn{5}{|l|}{ Altitude of residence (m) } \\
\hline $0-499$ & $697(70.2)$ & $64.7(60.2,68.9)$ & $35.3(31.1,39.8)$ & 0.043 \\
\hline $500-1499$ & $92(6.5)$ & $64.3(53.1,74.1)$ & $35.7(25.9,46.9)$ & \\
\hline 1500-2999 & $85(7.8)$ & $48.2(34.0,62.6)$ & $51.8(37.4,66.0)$ & \\
\hline 3000 or more & $171(15.5)$ & $54.6(44.2,64.7)$ & $45.4(35.3,55.8)$ & \\
\hline
\end{tabular}

Values are presented as \% (95\% confidence interval).

Estimates include the weights and 2017-2018 Food and Nutrition Surveillance by Life Stages survey sample specifications.

${ }^{1}$ The $p$-value was calculated using the chi-square test.

${ }^{2}$ Standardized by age according to the World Health Organization standard population. 
lence of PA level was calculated using the World Health Organization population (https://www.who.int/healthinfo/paper31.pdf). The Rao-Scott chi-square statistical test was used to evaluate differences between the variables of interest. To evaluate the magnitude of associations of the independent variables with the level of PA, a generalized linear model of the Poisson family with log link function was performed to estimate prevalence ratios (PRs) together with their $95 \% \mathrm{Cls}$. A bivariate model was constructed reporting the crude PRs, and all variables that obtained a statistically significant $p$-value $(p<0.20)$ were then included in the adjusted model. Multivariable analysis was performed to obtain adjusted prevalence ratios (aPRs). Likewise, the collinearity of the independent variables was evaluated using the variance inflation factor and a correlation matrix to detect and exclude highly correlated variables; no significant collinearity or correlation was found.

\section{Ethics Statement}

The National Institute of Health provided the anonymized database of the 2017-2018 VIANEV survey data after a request for access to public information (https://web.ins.gob.pe/es/ transparencia/solicitud-de-acceso-a-la-informacion-publica). The ENAHO 2017 microdata were obtained from the INEI website (http://iinei.inei.gob.pe/microdatos/). Ethical approval was not required for this research due to the public and anonymous nature of the data used.

\section{RESULTS}

A total of 1045 Peruvian adults were included in the analysis. The participants were predominantly female $(58.6 \%)$, within the age range of $18-29$ years (32.0\%), had a secondary educational level (38.5\%), self-identified as non-native (77.6\%) and had worked in the last week prior to the survey (69.7\%), while a smaller proportion of people had chronic diseases (42.4\%), had some limitation (1.6\%), lived in poverty (13.4\%) or extreme poverty $(2.3 \%)$, and had migrated from a rural to an urban area in the last 5 years (5.2\%). Regarding household characteristics, most participants resided in Metropolitan Lima (49.5\%) and at an altitude of 0-499 meters (70.2\%) (Table 1).

Of all the Peruvian adults included in the analysis, the agestandardized prevalence of low PA was $61.9 \%$. High proportions of low PA were found among female (66.3\%), those who had a higher education (67.9\%), those who lived in poverty $(62.4 \%)$ and those who had migrated to an urban area in the last 5 years (78.9\%). Regarding the location of households, the highest proportion of individuals who reported low PA was found in urban coastal areas (70.9\%), followed by the highlands (69.2\%) and urban areas in jungle (65.2\%) (Table 1). Table 2 presents the crude model of the factors associated with low PA, showing a significant association for all variables, with the exception of ethnicity, the presence of chronic diseases, and the presence of some limitation.

In the adjusted model, it was found that low PA was more likely in female (aPR, $1.17 ; 95 \% \mathrm{Cl}, 1.05$ to 1.31 ) and in individuals who had migrated from a rural to an urban area in the last 5 years (aPR, $1.21 ; 95 \% \mathrm{Cl}, 1.02$ to 1.44 ) than in males and those who had not migrated. Residing in the rural highlands (aPR, $0.49 ; 95 \% \mathrm{Cl}, 0.34$ to 0.72$)$ and jungle $(a \mathrm{PR}, 0.66 ; 95 \% \mathrm{Cl}, 0.50$ to 0.88 ) was associated with a reduced probability of having low PA compared to people residing in other geographic domains (Table 2).

\section{DISCUSSION}

The present study sought to determine the prevalence of low PA in the Peruvian population and to identify associated factors using the most recent population-based data on PA. It was found that 6 out of 10 Peruvian adults had low PA. In terms of associated factors, being a female and having migrated from a rural to an urban area in the last 5 years were associated with a higher probability of having low PA, while residing in rural areas of the jungle and highlands were associated with a reduced likelihood of having low PA.

In the present study, it was observed that more than half of Peruvian adults had low PA. This prevalence is higher than the global prevalence of low PA (27.5\%) and that of LAC (43.7\%). LAC is one of the regions with the highest prevalence of low PA, with Brazil (47.0\%), Costa Rica (46.1\%), and Colombia (44.0\%) having the highest reported levels of low PA, while the lowest prevalence rates are found in countries such as the Dominican Republic (21.6\%), Uruguay (22.4\%), and Chile (26.6\%) [5]. It should be noted that Peru was not included in the prevalence estimates for Latin American countries due to the lack of population-based data on PA, making it impossible to evaluate the status of PA in Peru compared to other regions [5]. However, the results of the present study demonstrate that the prevalence of low PA in the Peruvian population is one of the highest in the region, surpassing other South American countries such as Brazil and Colombia. 
Table 2. Crude and adjusted prevalence ratios of low physical activity

\begin{tabular}{|c|c|c|c|c|}
\hline Variables & Crude & $p$-value & Adjusted & $p$-value \\
\hline \multicolumn{5}{|l|}{ Sex } \\
\hline Male & 1.00 (reference) & & 1.00 (reference) & \\
\hline Female & $1.19(1.07,1.34)$ & 0.002 & $1.17(1.05,1.31)$ & 0.006 \\
\hline \multicolumn{5}{|l|}{ Age (y) } \\
\hline $18-29$ & 1.00 (reference) & & 1.00 (reference) & \\
\hline $30-39$ & $1.01(0.88,1.16)$ & 0.907 & $1.02(0.89,1.17)$ & 0.766 \\
\hline $40-49$ & $0.89(0.76,1.04)$ & 0.151 & $0.90(0.77,1.05)$ & 0.174 \\
\hline $50-59$ & $1.04(0.91,1.20)$ & 0.546 & $1.08(0.93,1.25)$ & 0.330 \\
\hline \multicolumn{5}{|l|}{ Educational level } \\
\hline Up to primary & 1.00 (reference) & & 1.00 (reference) & \\
\hline Secondary & $1.03(0.87,1.21)$ & 0.752 & $0.92(0.77,1.09)$ & 0.319 \\
\hline Higher education & $1.21(1.04,1.40)$ & 0.014 & $1.03(0.87,1.22)$ & 0.732 \\
\hline \multicolumn{5}{|l|}{ Ethnicity } \\
\hline Non-native & 1.00 (reference) & & Not included & \\
\hline Native & $0.98(0.85,1.13)$ & 0.758 & & \\
\hline \multicolumn{5}{|c|}{ Self-reported presence of chronic diseases } \\
\hline No & 1.00 (reference) & & Not included & \\
\hline Yes & $1.03(0.92,1.15)$ & 0.625 & & \\
\hline \multicolumn{5}{|c|}{ Self-reported presence of any physical, psychological, or cognitive limitations } \\
\hline No & 1.00 (reference) & & Not included & \\
\hline Yes & $0.93(0.61,1.41)$ & 0.717 & & \\
\hline \multicolumn{5}{|l|}{ Geographic domains } \\
\hline Urban coast & 1.00 (reference) & & 1.00 (reference) & \\
\hline Rural coast & $0.82(0.63,1.07)$ & 0.141 & $0.84(0.64,1.11)$ & 0.217 \\
\hline Urban highlands & $0.98(0.77,1.24)$ & 0.844 & $0.93(0.67,1.29)$ & 0.662 \\
\hline Rural highlands & $0.51(0.40,0.66)$ & $<0.001$ & $0.49(0.34,0.72)$ & $<0.001$ \\
\hline Urban areas in jungle & $0.92(0.73,1.16)$ & 0.471 & $0.90(0.71,1.14)$ & 0.396 \\
\hline Rural areas in jungle & $0.68(0.52,0.89)$ & 0.004 & $0.66(0.50,0.88)$ & 0.005 \\
\hline Metropolitan Lima & $0.92(0.79,1.08)$ & 0.301 & $0.94(0.80,1.10)$ & 0.422 \\
\hline \multicolumn{5}{|l|}{ Poverty } \\
\hline Extreme poverty & 1.00 (reference) & & 1.00 (reference) & \\
\hline Non-extreme poverty & $1.82(1.13,2.94)$ & 0.014 & $1.41(0.89,2.24)$ & 0.144 \\
\hline Non-poverty & $1.81(1.14,2.88)$ & 0.012 & $1.23(0.78,1.96)$ & 0.370 \\
\hline \multicolumn{5}{|l|}{ Worked in the last week } \\
\hline No & 1.00 (reference) & & 1.00 (reference) & \\
\hline Yes & $0.90(0.80,1.01)$ & 0.068 & $0.98(0.87,1.09)$ & 0.685 \\
\hline \multicolumn{5}{|c|}{ Urban migration in the last $5 y$} \\
\hline No & 1.00 (reference) & & 1.00 (reference) & \\
\hline Yes & $1.30(1.10,1.53)$ & 0.002 & $1.21(1.02,1.44)$ & 0.031 \\
\hline \multicolumn{5}{|l|}{ Altitude of residence (m) } \\
\hline $0-499$ & 1.00 (reference) & & 1.00 (reference) & \\
\hline $500-1499$ & $0.99(0.83,1.19)$ & 0.947 & $1.12(0.95,1.33)$ & 0.180 \\
\hline $1500-2999$ & $0.75(0.54,1.02)$ & 0.066 & $0.95(0.67,1.35)$ & 0.786 \\
\hline$\geq 3000$ & $0.84(0.69,1.03)$ & 0.101 & $1.14(0.82,1.59)$ & 0.424 \\
\hline
\end{tabular}

Values are presented as prevalence ratio (95\% confidence interval).

Estimates include the weights and 2017-2018 Food and Nutrition Surveillance by Life Stages survey sample specifications. 
In Peru, several studies have reported a prevalence of low PA ranging from $37.8 \%$ to $87.8 \%[17,19]$. Low-income and middle-income countries have the highest urban population growth and the largest urban area expansion (3 times greater than high-income countries) in the world [26], especially in LAC countries, where most of the population resides in urban areas. In this context, Peru has experienced rapid urbanization and unbalanced growth of cities that promote poverty, poor infrastructure, creation of informal settlements, lack of green spaces in the city, and an insecure perception of the environment, all of which promote sedentary lifestyles [27], increase the risk of developing NCDs and reduce life expectancy [28]. In this context, the implementation of effective interventions is needed to increase PA, especially in countries in which greater prevention measures are needed to decrease the burden of NCDs and reduce the number of deaths from preventable diseases [29].

In terms of associated factors, it was found that being female was associated with a higher probability of having low PA than males. This finding is similar to those reported in populations in Kenya [30], Iran [31], China [32], and Bangladesh [33], where it was found that female had a higher risk of physical inactivity than male. In Peru, a study conducted in the adult population reported that females had twice the risk of low PA compared to males [19]. Psychosocial factors (low level of selfefficacy, higher risk of associated injuries, less support from family and friends for participation in PA, and less motivation to be physically active) are involved in this association, increasing the risk of low PA in female compared to male [34]. Females also have socio-demographic and socioeconomic characteristics (low educational level, unemployment, and living in poverty) that increase the risk of low PA [35]. Therefore, prevention measures based on PA should be implemented and should be related to the psychosocial, socio-demographic, and socioeconomic factors of the female population in order to improve the quality of life and reduce the burden of NCDs in this population.

Likewise, it was found that residing in rural areas of the Peruvian jungle and highlands decreased the probability of having low PA. This finding is consistent with those reported in populations from Brazil [16], Chile [25], and South Africa [36], in which residing in a rural area was associated with a reduced risk of having low PA compared to living in urban areas. In Peru, two population-based studies-one in cities such as Puno (highlands region), a district of Lima (coast region) and
Tumbes (coast region), and the other conducted in the entire Peruvian territory - found that people residing in rural areas were less likely to have physical inactivity than people residing in urban areas $[17,19]$. This association between residing in a rural area and a low probability of physical inactivity is due to the fact that people (especially young male) residing in rural areas have higher levels of occupational activity related to active and manual farm work, and engage in more PA due to extensive walking because of the lack of motorized transportation and well-defined roads $[15,16]$. In addition, rural areas lack built-up spaces such as sidewalks, bike paths, public parks, street lighting, and recreational centers, leading to a decrease in leisure PA, which is beneficial for mental health [16]. Although the population residing in rural areas has a high level of work-related PA, leisure activities should be encouraged, specific spaces should be created for PA, and trained personnel should be available to promote healthy lifestyles in this population. Furthermore, these strategies are also necessary in urban areas, in which there is a high degree of sedentary lifestyles and a high prevalence of NCDs.

Finally, it was found that people who had migrated from a rural to an urban area in the last 5 years were more likely to have low PA. This finding is similar to that described in an Indian population, reporting that migration from rural to urban areas increased the risk of physical inactivity [37]. In Peru, a study conducted in Ayacucho (highlands region) and Lima (coast region) reported that migrating from a rural to an urban area increased the risk of physical inactivity by more than 20 fold [18]. This is because people who migrate from a rural area to a more urbanized area adopt unhealthy lifestyles (sedentary lifestyles, increased consumption of saturated fats and carbohydrates, weight gain, and high levels of stress) and live in unsafe environments, characterized by pollution, heavy traffic, high crime rates, and high population density [38]. These behavioral and environmental changes resulting from migration decrease people's physical activity and increase the risk of NCDs such as hypertension, diabetes, and obesity [39,40]. Thus, interventions targeting unhealthy lifestyles in people migrating from rural to urban areas and in people residing in urban contexts should be carried out to improve the health conditions and reduce the burden of disease from preventable diseases in these individuals.

The cross-sectional design of this survey precludes the establishment of causal inferences. In addition, recall bias and data imprecision are possible issues because this was a study 
of secondary data. Nonetheless, the 2017-2018 VIANEV was a population-based survey that assessed nutritional status at all stages of life and compliance with public interventions related to food and nutrition, such as PA. This survey used the short version of the IPAQ to measure PA levels, which despite possibly overestimating PA, has been widely evaluated and used in several studies worldwide [23]. Furthermore, this survey was carried out by previously trained personnel to avoid errors in the collection of information, thereby improving the quality and veracity of the data.

In conclusion, 6 out of 10 Peruvian adults were found to have low PA. Being a female and migrating from a rural to an urban area in the last 5 years were associated with a higher probability of having low PA, while residing in rural areas of the highlands and jungle was associated with a reduced probability of having low PA. Given this problem, cost-effective strategies focused on healthy lifestyles should be developed, especially in female and in urban areas, in which there is the highest prevalence of NCDs.

\section{CONFLICT OF INTEREST}

The authors have no conflicts of interest associated with the material presented in this paper.

\section{FUNDING}

None.

\section{ACKNOWLEDGEMENTS}

The authors are grateful to Donna Pringle for reviewing the language and style.

\section{AUTHOR CONTRIBUTIONS}

Conceptualization: AHV. Data curation: AHV. Formal analysis: AHV. Funding acquisition: None. Methodology: AHV. Project administration: AHV. Visualization: AHV, RVF. Writing - original draft: AHV, RVF. Writing - review \& editing: AHV, RVF.

\section{ORCID}

Akram Hernández-Vásquez https://orcid.org/0000-00031431-2526
Rodrigo Vargas-Fernández https://orcid.org/0000-00023310-8689

\section{REFERENCES}

1. Cleven L, Krell-Roesch J, Nigg CR, Woll A. The association between physical activity with incident obesity, coronary heart disease, diabetes and hypertension in adults: a systematic review of longitudinal studies published after 2012. BMC Public Health 2020;20(1):726.

2. Anokye NK, Trueman P, Green C, Pavey TG, Taylor RS. Physical activity and health related quality of life. BMC Public Health 2012;12:624.

3. Silva DA, Tremblay MS, Marinho F, Ribeiro AL, Cousin E, Nascimento $B R$, et al. Physical inactivity as a risk factor for all-cause mortality in Brazil (1990-2017). Popul Health Metr 2020;18 (Suppl 1):13.

4. Chen X, Wang Q, Zhang Y, Xie Q, Tan X. Physical activity and risk of breast cancer: a meta-analysis of 38 cohort studies in 45 study reports. Value Health 2019;22(1):104-128.

5. Guthold R, Stevens GA, Riley LM, Bull FC. Worldwide trends in insufficient physical activity from 2001 to 2016: a pooled analysis of 358 population-based surveys with 1.9 million participants. Lancet Glob Health 2018;6(10):e1077-e1086.

6. Sfm C, Van Cauwenberg J, Maenhout L, Cardon G, Lambert EV, Van Dyck D. Inequality in physical activity, global trends by income inequality and gender in adults. Int J Behav Nutr Phys Act 2020;17(1):142.

7. GBD 2019 Risk Factors Collaborators. Global burden of 87 risk factors in 204 countries and territories, 1990-2019: a systematic analysis for the Global Burden of Disease Study 2019. Lancet 2020;396(10258):1223-1249.

8. Ding D, Lawson KD, Kolbe-Alexander TL, Finkelstein EA, Katzmarzyk PT, van Mechelen W, et al. The economic burden of physical inactivity: a global analysis of major non-communicable diseases. Lancet 2016;388(10051):1311-1324.

9. GBD 2017 Disease and Injury Incidence and Prevalence Collaborators. Global, regional, and national incidence, prevalence, and years lived with disability for 354 diseases and injuries for 195 countries and territories, 1990-2017: a systematic analysis for the Global Burden of Disease Study 2017. Lancet 2018; 392(10159):1789-1858.

10. GBD 2017 Causes of Death Collaborators. Global, regional, and national age-sex-specific mortality for 282 causes of death in 195 countries and territories, 1980-2017: a systematic analysis 
for the Global Burden of Disease Study 2017. Lancet 2018;392 (10159):1736-1788.

11. United Nations. World urbanization prospects the 2011 revision; 2012 [cited 2021 Jul 1]. Available from: https://www. un.org/en/development/desa/publications/world-urbanization-prospects-the-2011-revision.html.

12. Martinez R, Lloyd-Sherlock P, Soliz P, Ebrahim S, Vega E, Ordunez $P$, et al. Trends in premature avertable mortality from non-communicable diseases for 195 countries and territories, 1990-2017: a population-based study. Lancet Glob Health 2020;8(4):e511e523.

13. Ranasinghe PD, Pokhrel S, Anokye NK. Economics of physical activity in low-income and middle-income countries: a systematic review. BMJ Open 2021;11(1):e037784.

14. Klepac Pogrmilovic B, Ramirez Varela A, Pratt M, Milton K, Bauman A, Biddle SJ, et al. National physical activity and sedentary behaviour policies in 76 countries: availability, comprehensiveness, implementation, and effectiveness. Int J Behav Nutr Phys Act 2020;17(1):116.

15. McCloskey ML, Tarazona-Meza CE, Jones-Smith JC, Miele CH, Gilman RH, Bernabe-Ortiz A, et al. Disparities in dietary intake and physical activity patterns across the urbanization divide in the Peruvian Andes. Int J Behav Nutr Phys Act 2017;14(1):90.

16. MartinsI RC, da Silval IC, Hallall PC. Physical activity in the rural population of Pelotas, Brazil: prevalence and associated factors. Rev Saude Publica 2018;52 Suppl 1:9s.

17. Miranda JJ, Carrillo-Larco RM, Gilman RH, Avilez JL, Smeeth L, Checkley W, et al. Patterns and determinants of physical inactivity in rural and urban areas in Peru: a population-based study. J Phys Act Health 2016;13(6):654-662.

18. Masterson Creber RM, Smeeth L, Gilman RH, Miranda JJ. Physical activity and cardiovascular risk factors among rural and urban groups and rural-to-urban migrants in Peru: a crosssectional study. Rev Panam Salud Publica 2010;28(1):1-8.

19. Tarqui Mamani C, Alvarez Dongo D, Espinoza Oriundo P. Prevalence and factors associated with low physical activity level among the Peruvian population. Nutr Clín Diet Hosp 2017; 37(4):108-115 (Spanish).

20. Zafra-Tanaka JH, Millones-Sánchez E, Retuerto-Montalvo MA Sociodemographic factors associated with physical activity and sedentary lifestyle in the adult Peruvian population. Rev Peru Epidemiol 2013;17(3):1-6 (Spanish).

21. Koetaka $\mathrm{H}$, Ohno Y, Morimoto $\mathrm{K}$. The change in lifestyle data during 9 years: the reliability and continuity of baseline health practices. Environ Health Prev Med 2013;18(4):335-340.
22. National Institute of Health. Physical activity of adults from 18 to 59 years old - VIANEV 2017-2018; 2020 [cited 2021 Jul 1]. Available from: https://web.ins.gob.pe/sites/default/files/Archivos/cenan/van/sala_nutricional/sala_3/informe_tecnico_ actividad_fisica_adultos_18_59_anos_vianev_2017_2018. pdf (Spanish).

23. Cleland C, Ferguson S, Ellis G, Hunter RF. Validity of the International Physical Activity Questionnaire (IPAQ) for assessing moderate-to-vigorous physical activity and sedentary behaviour of older adults in the United Kingdom. BMC Med Res Methodol 2018;18(1):176.

24. Pettee Gabriel KK, Morrow JR Jr, Woolsey AL. Framework for physical activity as a complex and multidimensional behavior. J Phys Act Health 2012;9 Suppl 1:S11-S18.

25. Díaz-Martínez X, Garrido A, Martínez MA, Leiva AM, Álvarez C, Ramírez-Campillo $\mathrm{R}$, et al. Correlates of physical inactivity: findings from the Chilean National Health Survey 2009-2010. Rev Med Chile 2017;145(10):1259-1267 (Spanish).

26. Sun L, Chen J, Li Q, Huang D. Dramatic uneven urbanization of large cities throughout the world in recent decades. Nat Commun 2020;11(1):5366.

27. Bauman AE, Reis RS, Sallis JF, Wells JC, Loos RJ, Martin BW, et al. Correlates of physical activity: why are some people physically active and others not? Lancet 2012;380(9838):258-271.

28. Barreto SM, Miranda JJ, Figueroa JP, Schmidt MI, Munoz S, Kuri-Morales PP, et al. Epidemiology in Latin America and the Caribbean: current situation and challenges. Int J Epidemiol 2012;41(2):557-571.

29. Saad MF, Cheah WL, Hazmi H. The effects of a 7000-step goal and weekly group walking program for overweight and obese elderly people in Sarawak, Malaysia: a quasi-experimental study. J Prev Med Public Health 2021;54(3):199-207.

30. Gichu M, Asiki G, Juma P, Kibachio J, Kyobutungi C, Ogola E. Prevalence and predictors of physical inactivity levels among Kenyan adults (18-69 years): an analysis of STEPS survey 2015. BMC Public Health 2018;18(Suppl 3):1217.

31. Sahebkar M, Heidarian Miri $\mathrm{H}$, Noormohammadpour $\mathrm{P}$, Akrami R, Mansournia N, Tavana B, et al. Prevalence and correlates of low physical activity in the Iranian population: national survey on non-communicable diseases in 2011. Scand J Med Sci Sports 2018;28(8):1916-1924.

32. Zhou Y, Wu J, Zhang S, Yan S, He L, Mkandawire N, et al. Prevalence and risk factors of physical inactivity among middle-aged and older Chinese in Shenzhen: a cross-sectional study. BMJ Open 2018;8(10):e019775. 
33. Moniruzzaman M, Ahmed MS, Zaman MM. Physical activity levels and associated socio-demographic factors in Bangladeshi adults: a cross-sectional study. BMC Public Health 2017; 17(1):59.

34. Edwards ES, Sackett SC. Psychosocial variables related to why women are less active than men and related health implications. Clin Med Insights Womens Health 2016;9(Suppl 1):47-56.

35. Zanchetta LM, Barros MB, César CL, Carandina L, Goldbaum M, Alves MC. Physical inactivity and associated factors in adults, São Paulo, Brazil. Rev Bras Epidemiol 2010;13(3):387-399.

36. Malambo P, Kengne AP, Lambert EV, De Villiers A, Puoane T. Prevalence and socio-demographic correlates of physical activity levels among South African adults in Cape Town and Mount Frere communities in 2008-2009. Arch Public Health 2016;74:54.
37. Sullivan R, Kinra S, Ekelund U, Bharathi AV, Vaz M, Kurpad A, et al. Socio-demographic patterning of physical activity across migrant groups in India: results from the Indian Migration Study. PLoS One 2011;6(10):e24898.

38. Rishi P, Khuntia G. Urban environmental stress and behavioral adaptation in Bhopal City of India. Urban Stud Res 2012;2012: 635061.

39. Bernabe-Ortiz A, Sanchez JF, Carrillo-Larco RM, Gilman RH, Poterico JA, Quispe R, et al. Rural-to-urban migration and risk of hypertension: longitudinal results of the PERU MIGRANT study. J Hum Hypertens 2017;31(1):22-28.

40. Ebrahim S, Kinra S, Bowen L, Andersen E, Ben-Shlomo Y, Lyngdoh $\mathrm{T}$, et al. The effect of rural-to-urban migration on obesity and diabetes in India: a cross-sectional study. PLoS Med 2010; 7(4):e1000268. 